\title{
ENTRE DEUSES E DEUS: A DIFERENÇA ENTRE OS DEUSES CONCEBIDOS PELA LÓGICA FILOSÓFICA E O DEUS DAS ESCRITURAS SAGRADAS
}

Among gods and God: the difference between gods conceived by philosophical logic and the

God of Holy Scriptures

Ricardo Pereira Santos Lima*

Resumo: O objetivo deste artigo é mostrar a diferença fundamental existente entre os deuses concebidos pela lógica e métodos filosóficos e o Deus religioso, ou seja, o Deus das Escrituras Sagradas. Para tanto, será necessário analisar os textos de pensadores como Descartes e Espinosa a fim de verificar que o deus por eles apresentado difere completamente do Deus que é objeto de fé e devoção de filósofos como Agostinho e Roger Bacon.

Palavras-chave: Deus. Crença-Razão. Filosofia-Religião.

\begin{abstract}
This paper aims to show the fundamental difference between the gods conceived by the logic and philosophical methods and the religious God, i.e. the God from Holy Scriptures. To do so, will be necessary to analyze the texts from thinkers like Descartes and Spinoza in order to verify that the god by them showed it is completely different from God whom is target of faith and devotion of philosophers like Augustine and Roger Bacon.
\end{abstract}

Keywords: God. Belief-Reason. PhilosophyReligion.

* Mestrando do Programa de Pós-graduação em Filosofia da Universidade Federal de Uberlândia (UFU).

Bolsista CAPES. Contato: filosofia.ricardo@gmail.com

\begin{tabular}{|l|c|c|c|c|c|}
\hline intuitio & ISSN & Porto Alegre & Vol.7- No.2 & $\begin{array}{c}\text { Novembro } \\
2014\end{array}$ & p. 214-225 \\
\hline
\end{tabular}


Entre deuses e Deus: a diferença entre os deuses concebidos pela lógica filosófica e o Deus das Escrituras Sagradas

\section{Introdução}

Falar sobre religião sem dúvida tem se tornado um grande passatempo para as pessoas. $\mathrm{O}$ tema é abordado tanto em conversas informais, quanto em conferências ou palestras especializadas sobre o assunto. Devido à sua importância, abrangência e número de problemas, a religião incorporou-se ao rol das questões filosóficas e, como tal, merecendo ser analisada sob uma perspectiva filosófica. Deste modo, não nos é estranho que vários cursos de graduação em Filosofia tenham uma disciplina dedicada ao estudo da religião.

Embora a investigação sobre a religião não seja uma tarefa exclusiva da filosofia - pois os teólogos não são necessariamente filósofos - existe, portanto, uma questão que, assim como na teologia, é uma das mais importantes da Filosofia, a saber: a existência de um Deus criador. Dito de outro modo: a existência de um princípio único, eterno e gerador de toda natureza. Como fora dito nas linhas acima, esta questão se encontra numa zona de interesse mútuo tanto da Filosofia quanto da Religião, cada qual abordando o problema a seu modo, em função de seu método. Ainda no que tange à proximidade das duas áreas em torno da questão, é corrente notar que muitos alunos que estão iniciando seus estudos em Filosofia acreditem que a Filosofia, amparada e munida do pensamento de filósofos tais como René Descartes e Espinosa, é a disciplina que dá a prova cabal da existência de Deus. Ademais, acreditam que a prova filosófica corrobora e até mesmo complementa a lacuna deixada pela Religião.

Não restam para todos aqueles que estudam Filosofia de que as reflexões tanto de Descartes quanto de Espinosa, são fundamentalmente concisas e extremamente claras, chegando realmente a convencer seu interlocutor sobre a existência de uma essência suprassensível que a tudo coordena. Contudo, é preciso ressaltar que o deus exposto nas obras destes dois pensadores - respectivamente Meditações sobre a Filosofia Primeira e Ética - é concebido de um modo completamente diferente daquele pensado por Agostinho e Roger Bacon ${ }^{1}$. Compreendemos que a base para a concessão da idéia

\footnotetext{
${ }^{1}$ Consideramos que as obras Meditações sobre a Filosofia Primeira e Ética não são obras teológicas, mas sim filosóficas. Porém muitos poderão atentar para o fato de que Descartes era cristão, como é possível de ser verificado em uma de suas cartas a Mersenne: "Para vossa questão de teologia, ainda que ultrapasse a capacidade de meu espírito, não me parece contudo fora de minha profissão, porque ela não toca de modo algum aquilo que depende da revelação, o nomeio propriamente teologia; mas ela é antes metafísica e se deve examinar pela razão humana. Ora, estimo que todos aqueles a quem Deus deu o uso dessa razão, são obrigados a empregá-la principalmente para procurar conhecê-lo e para conhecer a si mesmos. É por aí que tenho procurado começar meus estudos; e vos direi que eu nunca teria sido capaz de encontrar os fundamentos da física se eu não os tivesse procurado por essa via. Mas é a matéria que dentre todas eu mais tenho estudado, e na qual, graças a Deus, estou de algum modo satisfeito [...]" Cf. TEIXEIRA, Suellen Caroline. A ideia de liberdade em Descartes. 125f. Dissertação (Mestrado em Filosofia) - Faculdade de Filosofia da Universidade Federal de Uberlândia, 2014 p. 48. De modo que, mesmo sendo cristão, Descartes não fez uma filosofia Cristã, como afirma Gilson: "it is a Christian philosophy: this expression does not simply mean that his was the philosophy of a Christian [a filosofia de Agostinho], for a man may be a Christian and a philosopher without holding a Christian philosophy; such a thing has happened - Réné Descartes would be a quite good instance." Cf. GILSON,

\begin{tabular}{|c|c|c|c|c|c|}
\hline intuitio & ISSN & Porto Alegre & Vol.7- No12 & $\begin{array}{c}\text { Novembro } \\
2014\end{array}$ & p. 214-225 \\
\hline
\end{tabular}
}


Entre deuses e Deus: a diferença entre os deuses concebidos pela lógica filosófica e o Deus das Escrituras Sagradas

de Deus de Descartes e Espinosa prescinde - pelo menos nos textos citados nas linhas acima - das Escrituras Sagradas, fato que não ocorre nos textos de Agostinho e Roger Bacon.

Tomando como ponto de partida o fato da provável existência de uma entidade suprassensível, eterna, geradora e mantenedora do universo, buscaremos neste texto, apresentar as fundamentais diferenças existentes entre i) os modos particulares e filosóficos de concessão da ideia de Deus de René Descartes e Espinosa e ii) o modo de concessão e apresentação da idéia de Deus da religião. No tocante ao problema, mostraremos que, por causa da natureza de seus textos, o discurso de Descartes e Espinosa sobre Deus é algo puramente filosófico, distinto e distante de qualquer compromisso religioso.

\title{
1 A definiçãa do conceito "Deus"
}

É natural e racionalmente compreensível que o homem tenha historicamente acreditado na existência de uma entidade sobrenatural que supervisiona o mundo, a qual ele pôde chamar de "Deus", como evidencia Dilthey:

\begin{abstract}
As concepções religiosas do mundo brotam de uma peculiar conexão vital do homem. Para além do [elemento] dominável em que o homem primitivo como guerreiro, caçador, trabalhador e cultivador provoca mudanças no mundo exterior por meio de acções físicas num estabelecimento racional de fins, estende-se a região do não acessível a semelhante acção, do não alcançável pelo conhecimento. E como daí the parecem provir efeitos que lhe proporcionam a sorte na caça, o êxito guerreiro, as boas colheitas, tal como se descobre dependente de algo desconhecido na doença na loucura, na velhice, na mote, na perda da mulher, dos filhos, dos rebanhos, surge a técnica para influenciar este inapreensível mediante as suas orações, os seus dons, a sua sujeição, que não se domina com a sua atividade física. Deseja absorver em si as forças de seres superiores, obter uma boa relação com eles, unir-se a eles. As acções a tal dirigidas constituem o culto originário ${ }^{2}$.
\end{abstract}

Dilthey destaca que, conforme o desenvolvimento histórico do homem, o surgimento de cultos religiosos se deu de forma espontânea. Ora, como seria possível explicar, para o homem primitivo e sem ciência, a manifestação de diversos fenômenos naturais? Como seria possível explicar a morte? Dada a dificuldade em responder tais perguntas com base no mundo físico, foi necessário buscar respostas num mundo que se estende para além da natureza.

É fato que todas as línguas e todas as culturas têm um ou mais termos que são usados para se referir a "Deus" e, em muitos casos "deuses" ou divindades secundárias. Apesar de ser um item significativo e não menos importante na historiografia das religiões, este texto não se ocupará de tratar

Étienne. The Future of Augustinian Metaphysics. In: M. C. D'ARCY et al. St. Augustine: His Age, Life and Thought. New York: Meridian Books, 1957. pp. 289-290, grifo nosso.

${ }^{2}$ DILTHEY, Wilhelm. Os Tipos de Concepção de Mundo. Tradução de Artur Morão. 1992, p. 23

\begin{tabular}{|c|c|c|c|c|c|}
\hline intuitio & ISSN & Porto Alegre & Vol.7- No.2 & $\begin{array}{c}\text { Novembro } \\
2014\end{array}$ & p. 214-225 \\
\hline
\end{tabular}


Entre deuses e Deus: a diferença entre os deuses concebidos pela lógica filosófica e o Deus das Escrituras Sagradas

de tais divindades secundárias, menores ou artísticas ${ }^{3}$. Compreendemos que o ponto de indefinição filosófica e religiosa surge quando ambos os discursos se referem a "um" ser que é chamado de "Deus". Não haveria ponto de intersecção entre a Filosofia e a Religião caso divindades secundárias fossem incluídas, pois não mais se estaria falando sobre "um" princípio gerador, mas sim sobre “vários" princípios, que são muitas vezes adiáforos.

Deste modo, para a prossecução deste texto, considera-se que "Deus" é o nome pessoal de um Deus Uno, um ser que é imanente e ao mesmo tempo transcendente, onisciente, onipresente, onipotente e eterno. Este Deus é sensorialmente inacessível e por isso deve-se levar em consideração que os adjetivos anteriores, por mais abrangentes que sejam, são extremamente limitados quando procuram se referir a Deus. Todos os seres vivos que povoam o mundo - sejam eles dotados de razão ou não - são seres finitos e imperfeitos que jamais poderão alcançar, expressar ou explicar completa e pormenorizadamente aquilo que é infinito e perfeito por excelência. É por este fato que se pode afirmar que conhecemos os atributos divinos através do princípio de negação ou exclusão, tal como reconheceu Moisés de Maimônides em seu Guia dos Perplexos:

Saiba que a verdadeira descrição de Deus ocorre por meio de atributos negativos, que dispensam uma linguagem imprecisa e não implicam qualquer tipo de imperfeição no que se refere a Ele. Na verdade, Sua descrição por meio de atributos positivos implica polivalência e imperfeição ${ }^{4}$.

Essa dificuldade em caracterizar Deus se traduz na certeza da evidência de que nenhum outro ser ou essência pode se chamar "Deus". O conceito não admite plural ou gênero. Isso somente atesta sua singularidade quando comparado com o conceito "deus", que admite um plural, como em "deuses", e gênero, como em "deusa". Deste modo, como foi dito anteriormente, este texto tem como objeto de reflexão somente o conceito "Deus", tal como é conhecido nas grandes religiões monoteístas e tal como é citado pelos pensadores como Descartes, Espinosa, Agostinho e Roger Bacon.

Importa ressaltar que é reconhecida neste trabalho a fundamental diferença existente entre as três grandes religiões monoteístas - judaísmo, cristianismo e islamismo - no que diz respeito à crença da "Unidade" e "Univocidade" de Deus, contudo, não é o objetivo do texto trazer as explanações sobre essas diferenças substanciais, dado que tais diferenciações contribuiriam somente para um entendimento pormenorizado das características exclusivas de cada religião, o que não é o foco desta exposição. Destarte, adotar-se-á para a compreensão deste escrito somente a concepção mais básica e

\footnotetext{
${ }^{3}$ Logo no início de seu $O$ nascimento da tragédia, Nietzsche utiliza o termo Kunstgottheiten (divindades artísticas) para se referir aos deuses gregos Apolo e Dioníso. "An ihre beiden Kunstgottheiten, Apollo und Dionysus [...]". Cf. NIETZSCHE, Friedrich. Die Geburt der Tragödie. Unzeitgemässe Betrachtungen I-IV. Nachgelassene Schriften 1870-1873. Kritische Studienausgabe Herausgegeben von Giorgio Colli und Mazzino Montinari. Berlin: Walter de Gruyter, 1999. Band 1. p. 25.

${ }^{4}$ MAIMONIDES, Moisés. O Guia dos Perplexos: Parte I. Tradução por Uri Lam. São Paulo: Landy, 2003. p. 187.

\begin{tabular}{|c|c|c|c|c|c|}
\hline intuitio & ISSN & Porto Alegre & Vol.7 - No.2 & $\begin{array}{c}\text { Novembro } \\
2014\end{array}$ & p. 214-225 \\
\hline
\end{tabular}
}


Entre deuses e Deus: a diferença entre os deuses concebidos pela lógica filosófica e o Deus das Escrituras Sagradas singularista do monoteísmo: aquela que afirma que Deus é Um. Prescindindo, portanto, do problema da natureza trinitária ${ }^{5}$ do Deus crido pelos católicos.

Doravante, considera-se o princípio islâmico que afirma que judeus, cristãos e muçulmanos servem o mesmo Deus:

Dizei: Cremos em Deus, no que nos tem sido revelado, no que foi revelado a Abraão, a Ismael, a Isaac, a Jacó e às tribos; no que foi concedido a Moisés e a Jesus e no que foi dado aos profetas por seu Senhor; não fazemos distinção alguma entre eles, e nos submetemos a Ele $^{6}$.

\section{O Deus concebido filosoficamente e o Deus religioso não são necessariamente os mesmos}

Feitas as considerações anteriores, faz-se forçoso introduzir o tema que carrega o título deste trabalho, a saber, por que o deus concebido por meio de argumentos filosóficos, alheio às Sagradas Escrituras, não pode ser reconhecido como o Deus da fé. David Hume em seu texto História natural da religião introduz o primeiro argumento que confirma esta tese:

A doutrina de um deus supremo e único, autor da natureza, é muito antiga e propagou-se entre nações importantes e populosas, onde homens de todas as classes e de todas as posições sociais a abraçaram. Mas aquele que pensar que seu êxito se deve à força predominante das razões invencíveis, sobre as quais ela é indubitavelmente fundada, mostra-se pouco familiarizado com a ignorância e a estupidez das pessoas e seus incuráveis preconceitos a favor de suas superstições particulares. Ainda hoje, e na EUROPA, se perguntássemos a um homem do povo por que ele crê em um criador do mundo onipotente, ele jamais mencionaria a beleza das causas finais, que ele ignora totalmente; também não estenderia a mão para nos convidar a contemplar a flexibilidade e a variedade das articulações de seus dedos, da curvatura uniforme de todos eles, do equilibro que mantém com o polegar, das partes delicadas e carnosas da palma e de todas as outras circunstâncias que tornam tal membro apto para a função para a qual foi destinado. Ele está acostumado a todas essas coisas há muito tempo e as olha com despreocupação e indiferença. Falará da morte repentina e inesperada de alguém, da queda e contusão de outro, da seca extrema de uma tal estação ou do frio e das chuvas de uma outra. ${ }^{7}$

Hume, na citação anterior, expõe a notável diferença entre o incrédulo pensador e o crente. O primeiro procura justificar seus argumentos via bases racionais ou filosóficas, ao passo que o segundo apenas busca entender, embasado pela fé, todas as adversidades sobrenaturais que possam se estender diante dele.

É importante ressaltar que não se trata de afirmar que um esteja certo e o outro errado. Isto é, que o filósofo diga a verdade porque seus argumentos, logicamente estruturados, são embasados pelo

\footnotetext{
${ }^{5}$ Segundo Weiss-Rosmarin: “O Trinitarismo, que significa a crença e fé no 'Pai, Filho e Espírito Santo' é tão fundamental e relevante para todas as foras e denominações de cristianismo, como é contrário a tudo o que o Judaísmo considera sagrado." Cf. WEISS-ROSMARIN, Trude. Judaísmo e Cristianismo: as diferenças. Trad. por Silvia Waldsztejn. São Paulo: Sêfer, 1996. p. 18.

${ }^{6}$ ALCORÃO, Sura 2: 136

${ }^{7}$ HUME, David. História natural da religião. Trad., apresentação e notas por Jaimir Conte. São Paulo: Editora UNESP, 2005. pp. 59-60.

\begin{tabular}{|l|c|c|c|c|c|}
\hline intuitio & ISSN & Porto Alegre & Vol.7 $-\mathrm{N}^{\mathrm{o}} .2$ & $\begin{array}{c}\text { Novembro } \\
2014\end{array}$ & p. 214-225 \\
\hline
\end{tabular}
}


Entre deuses e Deus: a diferença entre os deuses concebidos pela lógica filosófica e o Deus das Escrituras Sagradas

uso da livre razão, ou que o crente está correto porque seu conhecimento se origina de uma verdade expressa pelo seu "mestre interior", que é iluminado por Deus, como afirmaria Agostinho. A emissão deste tipo de juízo de valor não acrescenta riqueza ao tema, mas ao contrário, o empobrece fechando seus horizontes e limitando a compreensão do problema filosófico, que é universal. O elemento importante que se destaca na citação de David Hume é, essencialmente, a diferença que ambos os discursos reservam para o componente "religião". Isto é, o discurso do crente é reconhecido pela presença plena da religião, ao passo que o discurso do filósofo é caracterizado pela total ausência dela. A única ressalva é o período reconhecido por Idade Média: o único momento da História em que os discursos filosóficos e religiosos se imiscuíram. David Hume situava-se num período histórico em que os tenros laços entre Filosofia e Religião, outrora criados e fortalecidos pelo medievo, já estavam enfraquecidos e praticamente rompidos.

Pouco antes desse rompimento, aparentemente pleno, a modernidade conheceu alguns pensadores que, apesar de não serem filósofos da cristandade, tinham em sua filosofia traços que lembravam àquela outrora feita pelos padres da Igreja. René Descartes, um exemplo desta categoria de pensadores, em suas Meditações sobre a Filosofia Primeira, concebe o ser de Deus do seguinte modo:

16. [...] Pois, não há dúvida de que as que mostram substâncias são algo mais e contêm, por assim dizer, mais realidade objetiva, isto é, participam por representação de mais graus de ser ou de perfeição do que as que só representam modos ou acidentes. Por sua vez, aquela pela qual entendo um certo Deus supremo, eterno, infinito, imutável, onisciente, onipotente, criador de todas as coisas que estão fora dele, seguramente tem em si mais realidade objetiva do que as idéias pelas quais se mostram as substâncias finitas. ${ }^{9}$

24. E, assim, a ideia de Deus permanece a única em que se deve considerar se há algo que não poderia provir de mim. Entendo pelo nome de Deus certa substância infinita, independente, eterna, imutável, sumamente inteligente e sumamente poderosa pela qual eu mesmo fui criado e tudo o que mais existente, se existe alguma outra coisa. Todas essas coisas são tais que quanto mais cuidadosamente

\footnotetext{
${ }^{8}$ Segundo o bispo de Hipona no diálogo De Magistro (I, XII, 40), a busca da verdade, consiste no concílio entre a fé e a razão. A fé toma o papel do "mestre interior" e a razão é a nossa capacidade natural de captar e trabalhar com o inteligível. Segundo Agostinho: "Quando, porém, se trata daquelas coisas que contemplamos com a mente, isto é, com o intelecto e a razão, falamos sem dúvida das coisas que contemplamos naquela luz interior da Verdade, de que é iluminado e goza aquele que se chama 'homem interior' [...] Por conseguinte, tampouco a este, que intui a verdade, nada o ensino dizendo coisas verdadeiras, pois não é ensinado pelas minhas palavras, mas pelas coisas mesmas, que são evidentes porque Deus as manifesta interiormente. (Cum vero de iis agitur quae mente conspicimus, id est intellectu atque ratione, ea quidem loquimur quae praesentia contuemur in illa interiore luce veritatis, qua ipse qui dicitur homo interior, illustratur et fruitur [...] Ergo ne hunc quidem doceo vera dicens, vera intuentem; docetur enim non verbis meis, sed ipsis rebus, Deo intus pandente, manifestis: itaque de his etiam interrogatus respondere posset.) Cf. AGOSTINHO, Santo. De Magistro. Trad., introd. e comentários por Bento Silva Santos. Petrópolis: Editora Vozes, 2009. p. 151.

${ }^{9}$ DESCARTES, René. Meditações sobre a Filosofia Primeira. Trad., nota prévia e revisão por Fausto Castilho. Campinas: Editora da Unicamp, 2004. Edição bilíngue. p.81 ([...] Nam proculdubio illae quae substantias mihi exhibent, majus aliquid sunt, atque, ut ita loquar, plus realitatis objectivae in se continent, quam illae quae tantum modos, sive accidentia, representant; \& rursus illa per quam summum aliquem Deum, aeternum, infinitum, omniscium, omnipotentem, rerumque omnium, quae praeter ipsum sunt, creatorem intelligo, plus profecto realitatis objectivae in se habet, quam illae per quas finitae substantiae exhibentur.)

\begin{tabular}{|c|c|c|c|c|c|}
\hline intuitio & ISSN & Porto Alegre & Vol.7- No. 2 & $\begin{array}{c}\text { Novembro } \\
2014\end{array}$ & p. 214-225 \\
\hline
\end{tabular}
}


Entre deuses e Deus: a diferença entre os deuses concebidos pela lógica filosófica e o Deus das Escrituras Sagradas

lhes presto atenção, tanto menos parece que elas possam provir somente de mim. Por isso, do que foi dito deve-se concluir que Deus existe necessariamente. ${ }^{10}$

Não restam dúvidas acerca da capacidade argumentativa de Descartes. A maestria e desenvoltura de seus argumentos, utilizados para comprovar a existência de Deus, podem colocar em dúvida até mesmo o mais incrédulo dos homens. A dúvida, no caso específico do pensamento cartesiano, é o elemento basilar para a construção do conhecimento verdadeiro. Entrementes, não encontrará êxito no seu projeto, aquele que desejar se converter ao teísmo através da exposição dos argumentos cartesianos. No máximo, este sujeito estará louvando um "deus cartesiano" e não em um deus religioso. Afinal é necessário atentar para o fato de que apesar da descrição cartesiana remeter a todas aquelas características de um Deus do monoteísmo - no caso, aquele que é louvado pelo judaísmo, cristianismo e islamismo - as palavras de Descartes, prescindem da característica principal do discurso religioso: a revelação como fonte e guia do pensamento racional.

Enfatiza-se que um cético religioso, nunca se deixará converter pela argumentação racional. Do mesmo modo, salienta-se que um religioso convicto nunca se deixará levar pela pomposa e bem orquestrada argumentação de um douto incrédulo. Deste modo, reitera-se que o atributo necessário para a crença no Deus religioso é a fé e a revelação, e não a razão. O deus concebido e apresentado por Descartes, deste modo, não passa de uma abstração metafísica. Isto é, o deus cartesiano é filosófico, criado a partir de sua filosofia metódica com o objetivo principal de auxiliar no percurso filosófico das Meditações a fím de evitar o solipsismo ${ }^{11}$, provando a existência do mundo exterior através do conceito de realidades objetivas ${ }^{12}$.

Assim como Descartes, Espinosa é um pensador moderno cuja parte de seu pensamento pode desencadear certos equívocos de interpretação. Em sua Ética, Espinosa descreve de modo lógico e filosófico algumas das características de Deus, características tais que se assemelham muito àquelas já conhecidas pelos religiosos:

$\mathrm{P}$ 14. Como Deus é um ente absolutamente infinito, do qual nenhum atributo que exprima a essência de uma substância pode ser negado, e como ele existe necessariamente, se existisse alguma substância além de Deus, ela deveria ser

\footnotetext{
${ }^{10}$ DESCARTES, René. Meditações sobre a Filosofia Primeira. Trad., nota prévia e revisão por Fausto Castilho. Campinas: Editora da Unicamp, 2004. Edição bilíngue, p. 91 (Itaque sola restat Idea Dei, in qua considerandum est an aliquid sit quod a me ipso non potueri proficisci. Dei nomine intelligo substantiam quandam infinitam, independentem, summe intelligentem, summe potentem, \& a qua tum ego ipse, tum aliud omne, si quid aliud extat, quodcumque extat, est creatum. Quae sane omnia tália sunt ut, quo diligentius attendo, tanto minus a me solo profecta esse posse videantur. Ideoque ex antecitis, Deum necessario existere; est concludendum.)

${ }^{11} \mathrm{O}$ solipsismo designa o retraimento da consciência do indivíduo em si mesma, tanto em relação ao mundo exterior quanto a outras consciências. O solipsismo é consequencia direta da crença dogmática do cogito cartesiano.

${ }^{12}$ Consoante a Descartes nas Segundas Respostas: "Para a realidade objetiva de uma ideia entendo a entidade ou o ser da coisa representado pela ideia tanto quanto essa entidade está na ideia; da mesma maneira, pode-se dizer de uma perfeição objetiva, ou de um artífice objetivo, etc. Pois tudo o que concebemos como estando nos objetos das ideias, tudo isso está objetivamente, ou por representação nas ideias mesmas." $C f$. TEIXEIRA, Suellen Caroline. A ideia de liberdade em Descartes. 125f. Dissertação (Mestrado em Filosofia) - Faculdade de Filosofia da Universidade Federal de Uberlândia, 2014 p. 48.
}

\begin{tabular}{|l|c|c|c|c|c|}
\hline intuitio & ISSN & Porto Alegre & Vol.7 - No. 2 & $\begin{array}{c}\text { Novembro } \\
2014\end{array}$ & p. 214-225 \\
\hline
\end{tabular}


Entre deuses e Deus: a diferença entre os deuses concebidos pela lógica filosófica e o Deus das Escrituras Sagradas

explicada por algum atributo de Deus e existiriam, assim, duas substâncias de mesmo atributo, o que é absurdo. Portanto, não pode existir e, consequentemente, tampouco pode ser concebida nenhuma substância além de Deus. Pois, se pudesse ser concebida, ela deveria necessariamente ser concebida como existente. Mas isso é absurdo. Logo, além de Deus, não pode existir nem ser concebida nenhuma substância. ${ }^{13}$

P 18. Tudo o que existe, existe em Deus, e por meio de Deus deve ser concebido; portanto, Deus é causa das coisas que nele existem, que era o primeiro ponto. Ademais, além de Deus, não pode existir nenhuma substância, isto é, nenhuma coisa, além de Deus, existe em si mesma, que era o segundo ponto. Logo, Deus é causa imanente, e não transitiva, de todas as coisas. ${ }^{14}$

Não seria difícil confundir os excertos supracitados de Espinosa com os de um pensador da Escolástica Medieval, como Tomás de Aquino, caso os excertos anteriores não tivessem sido apresentados como sendo de Espinosa. O pensamento de Espinosa é sistemático e, assim como Tomás de Aquino, frequentemente trilha o caminho do rigor lógico e da evidência causal para afirmar e justificar a existência de Deus e de seus atributos. No entanto, a Suma de Teologia de Tomás de Aquino é reconhecida como um pilar da filosofia Cristã, ao passo que a Ética de Espinosa não goza do status de ser uma obra basilar do judaísmo.

Novamente, reitera-se que não é prudente admitir que a argumentação lógica, postulados e definições sejam capazes de demonstrar e provar a existência de um Deus religioso. Caso assim o fosse, dever-se-ia admitir da mesma maneira que as proposições expostas na Elementatio Theologica de Proclo e no anônimo Liber de Causis ${ }^{15}$ sejam também exortações de confirmação da existência de um Deus Uno e religioso, o que de fato não ocorre. Resulta, portanto, que o discurso filosófico não é capaz de versar sobre o Deus da fé.

A consequência anterior poderia até confirmar-se como verdadeira caso não houvesse exemplos que a contradissesse. Um exemplo de discurso filosófico que acessa o conhecimento de Deus é o de Agostinho, sua filosofia banhada pela fé e pela escritura revela ao leitor a crença indelével em um Deus religioso. Ao contrário de Descartes e Espinosa, Agostinho expõe sua crença em Deus

${ }^{13}$ SPINOZA, Benedictus de. Ética. $2^{\text {a }}$ ed. Trad. e notas por Tomaz Tadeu. Belo Horizonte: Autêntica Editora, 2008. Edição bilíngüe. p. 29-31 (P. XIV - Cum Deus si tens absolute infinitum, de quo nullum attributum, quod essentiam substantiae exprimit, negari potest, isque necessario existat, si aliqua substantia praeter Deum daretur, ea explicari deberet per aliquod attributum Dei, sicque duae substantiae eiusdem attributi existerent, quod est absurdum; adeoque nulla substantia extra Deum dari potest et consequenter non etiam concipi. Nam si posset concipi, deberet necessario concipi, ut existens; atqui hoc est absurdum. Ergo extra Deum nulla dari, neque concipi potest substantia.)

${ }^{14}$ SPINOZA, Benedictus de. Ética. $2^{\text {a }}$ ed. Trad. e notas por Tomaz Tadeu. Belo Horizonte: Autêntica Editora, 2008. Edição bilíngüe, p. 43 (P. XVIII - Omnia quae sunt in Deo sunt et per Deum concipi debent, adeoque Deus rerum, quae in ipso sunt, est causa; quod est primum. Deinde extra Deum nulla potest dari substantia, hoc est res, quae extra Deum in se sit; quod erat secundum. Deus ergo est omnium rerum causa immanens, non vero transiens.)

${ }^{15}$ A Elementatio Theologica é uma obra do autoria de neo-platônico Proclo, o Liber de Causis, por sua vez, é uma obra de autoria desconhecida, oriunda do círculo de al-Kindi. Ambas têm como tese principal o problema da Causa Primeira, a qual pode ser entendida como a causa criadora de todas as coisas existentes, sem ela mesma ser causada por alguma coisa, diferentemente do Primeiro Motor Imóvel de Aristóteles, o qual não cria as coisas, mas as move.

\begin{tabular}{|l|c|c|c|c|c|}
\hline intuitio & ISSN & Porto Alegre & Vol.7 - No. 2 & $\begin{array}{c}\text { Novembro } \\
2014\end{array}$ & p. 214-225 \\
\hline
\end{tabular}


Entre deuses e Deus: a diferença entre os deuses concebidos pela lógica filosófica e o Deus das Escrituras Sagradas

valendo-se de passagens da Escritura Sagrada, como por exemplo, no capítulo 24 do Livro XXII de sua Cidade de Deus, em que cita o Apóstolo Paulo: "Nem quem planta é alguma coisa, nem quem rega, mas quem dá o crescimento: Deus." "16. Na passagem, Agostinho compreende que Deus é a causa última da criação dos homens, e como tal, é a mais importante dentre todas as causas que venham a agir sobre o homem. Esta passagem, e o pensamento de Agostinho se alinham a algumas proposições encontradas no Liber de Causis, as quais afirmam que:

I. Toda causa primeira influência mais o seu efeito do que a causa universal segunda. ${ }^{17}$

II. Por isso, quando a causa universal segunda retira a sua força de alguma coisa, a causa universal primeira não a retira desta. ${ }^{18}$

III. A razão disso está no fato de a causa universal primeira agir sobre o efeito da causa segunda, antes mesmo que sobre ela venha a agir a causa universal segunda que a acompanha. ${ }^{19}$

IV. Quando, então, a causa segunda, que acompanha o efeito, age, sua ação não escapa à causa universal primeira que está acima dela. ${ }^{20}$

V. E quando a causa segunda, que segue o efeito, fica dele separada, a causa primeira, que está acima da segunda, não é separada dele, porque é sua causa. ${ }^{21}$

Ora, tanto Agostinho quanto o Liber de Causis, podem ser utilizados para falar sobre o mesmo assunto, a diferença elementar existente entre ambos repousa no fundamento utilizado por cada um: Agostinho não expôs um argumento, um postulado ou uma definição concebidos por princípios de ordem lógica, mas ao contrário, utilizou a simplicidade dos textos da Escritura, ao passo que as proposições do Liber de Causis, se apartam completamente do Texto Sagrado. Somente o discurso que é carregado pela Escritura é capaz de alcançar o conhecimento do Deus da fé. Muitos poderão objetar contra esse fato, no entanto não existe nenhuma contradição em afirmar que a fé auxilia o pensamento racional, como afirma Gilson:

Ele [Agostinho] sustenta a fé para engendrar a razão, e o dogma, tomado como tal, para engendrar a filosofia. De modo algum ele confunde crença e conhecimento, ou até mesmo filosofia e teologia, para acreditar no dogma, e deduzir dele as conseqüências que isso implica, é, para ele, não mais filosofante do que seria para qualquer um dos nossos positivistas contemporâneos. Mas para deixar a razão sair para encontrar a fé, a fim de explicar racionalmente sua fé para ele mesmo, para

\footnotetext{
${ }^{16}$ BÍBLIA SAGRADA, 1 Cor. III, 7

${ }^{17}$ O Livro das Causas; tradução e introdução por Jan Gerard Joseph ter Reegen. Porto Alegre: EDIPUCRS, 2000 (Omnis causa primaria plus est influens super causatum suum quam causa universalis secunda).

${ }^{18}$ O Livro das Causas; tradução e introdução por Jan Gerard Joseph ter Reegen. Porto Alegre: EDIPUCRS, 2000 (Cum ergo removet causa universalis secunda virtutem suam a re, causa universalis prima non aufert virtutem suam ab eo.)

${ }^{19}$ O Livro das Causas; tradução e introdução por Jan Gerard Joseph ter Reegen. Porto Alegre: EDIPUCRS, 2000 (Quod est quia causa universalis prima agit in causatum causae secundae, antequam agat in ipsum causa universalis secunda quae sequitur ipsum.)

${ }^{20}$ O Livro das Causas; tradução e introdução por Jan Gerard Joseph ter Reegen. Porto Alegre: EDIPUCRS, 2000 (Cum ergo removet causa secunda quae sequitur causatum, non excusat ipsius actio a causa prima quae est supra ipsam.)

${ }^{21}$ O Livro das Causas; tradução e introdução por Jan Gerard Joseph ter Reegen. Porto Alegre: EDIPUCRS, 2000 (Et quando separatur causa secunda a causato, quae sequitur ipsum, non separatur ab eo prima quae est supra ipsam, quoniam est causa ei.)

\begin{tabular}{|l|c|c|c|c|c|}
\hline intuitio & ISSN & Porto Alegre & Vol.7- No.2 & $\begin{array}{c}\text { Novembro } \\
2014\end{array}$ & p. 214-225 \\
\hline
\end{tabular}
}


Entre deuses e Deus: a diferença entre os deuses concebidos pela lógica filosófica e o Deus das Escrituras Sagradas

construir, sob a influência de uma luz sobrenatural e transcendente, um sistema de idéias os quais, embora puramente racionais nelas mesmas, seriam impossíveis sem essa luz, é o que ele sempre pretendeu fazer, e o que ele fez com esplêndido sucesso $^{22}$.

Já no final da Idade Média, até mesmo a filosofia científica de Roger Bacon pode ser citada como grande exemplo de discurso racional e filosófico que faz menção a um Deus religioso sem sofrer rachaduras em sua estrutura.

Conforme a doutrina epistemológica de Bacon, existem duas formas de se adquirir conhecimento: uma pela razão e outra pela experiência. Nem uma nem outra bastam por si próprias, de modo que ambas devem se completar, pois, segundo ele, "a demonstração conclui e faz com que admitamos a conclusão, mas não nos certifica nem impede a dúvida, de modo que faça descansar nossa mente na intuição da verdade, se não encontra sua confirmação na experiência” ${ }^{23}$. Bacon utiliza uma situação simples e corriqueira para ilustrar e reforçar sua teoria: a de que ninguém pode saber que o fogo queima e destrói sem antes ter tido contato com ele. Mesmo que existam inúmeros argumentos racionais que corroborem para essa tese, nossa alma não se satisfaz enquanto não tiver experimentado seus efeitos nada aprazíveis. ${ }^{24}$

Bacon reserva à experiência a qualidade de ser a única ferramenta capaz de fornecer ao homem a possibilidade de conhecimento da verdade. A experiência é um instrumento bivalente, capaz de se reportar tanto às coisas naturais quanto às coisas sobrenaturais e divinas. Assim, Bacon sustenta que existem dois tipos de experiência: a externa e a interna. A experiência externa consiste na observação dos fatos dados através dos sentidos, a experiência interna, por sua vez, é dada através da iluminação divina. Essa luz divina é Deus, e ela atua em nossa alma na ocasião de apreensão de cada conhecimento, como evidenciam Boehner e Gilson: ${ }^{22}$ GILSON, Étienne. The Future of Augustinian Metaphysics. In: M. C. D'ARCY et al. St. Augustine: His Age,
Life and Thought. New York: Meridian Books, 1957. p. 290, tradução nossa. (He holds faith to engender reason,
and dogma, taken as such, to engender philosophy. Not by any means that he confuses belief and knowledge, or
even philosophy and theology, for to believe in the dogma, and to deduce from it the consequences it implies, is,
for him, no more philosophizing than it would be for any of our contemporary positivists. But to let reason go
out to meet faith, to account rationally for his faith to himself, to construct, under the influence of a supernatural
and transcendent light, a system of ideas which, though purely rational themselves, would yet be impossible
without this light, is what he had always meant to do, and what he did with wonderful success.)
${ }^{23}$ GUERRERO, Rafael Ramón. Historia de la Filosofía Medieval. Madrid: Akal Ediciones, 2002. p. 205
${ }^{24}$ Nas palavras de Bacon: "Portanto, se algum homem que nunca viu o fogo \{experimentou\}, diante de
argumentos suficientes de que o fogo queima, fere destrói as coisas; por causa disso, nunca descansa esta alma
que ouve, nem evita o fogo antes de colocar-lhe a mão, ou alguma outra coisa no fogo, de tal maneira que [se]
prova pela experiência aquilo que o argumento ensina. Mas, tendo assumido a experiência da combustão, a alma
[se] certifica e descansa no fulgor da verdade. Logo, o argumento não é suficiente, mas a experiência [o é]." (Si
enim aliquis homo qui nunquam vidit ignem \{probaverit\} per argumenta sufficientia quod ignis comburit et
laedit res et destruit, nunquam propter hoc quiesceret animus audientis, nec ignem vitaret antequam poneret
manum vel rem combustibilem ad ignem, ut per experientiam probaret quod argumentum edocebat. Sed
assumpta experientia combustionis certificatur animus et quiescit in fulgore veritatis. Ergo argumentum non
sufficit, sed experientia.) Cf. BACON, Roger. Opera Maius VI, 1. Disponível em <
http://www.mlat.uzh.ch/MLS/ >. Acesso em: 23 out. 2013. Tradução nossa.

\begin{tabular}{|l|c|c|c|c|c|}
\hline intuitio & ISSN & Porto Alegre & Vol.7 - No.2 & $\begin{array}{c}\text { Novembro } \\
2014\end{array}$ & p. 214-225 \\
\hline
\end{tabular}


Entre deuses e Deus: a diferença entre os deuses concebidos pela lógica filosófica e o Deus das Escrituras Sagradas

Por isso o entendimento deve recorrer a um segundo tipo de experiência: à iluminação interior, graças à qual as ciências deste mundo foram comunicadas aos santos Patriarcas e Profetas, bem como a numerosos cristãos: "Nam gratia fidei illuminat multum, et divinae inspirationes, non solum in spiritualibus, sed corporalibus et scientiis philosophiae"25. (1995, p. 389)

Esse excerto mostra que a filosofia de Bacon, apesar de ser extremamente experimental e científica, também não se afasta da religião e da fé. A célebre frase agostiniana: "Ut intellegas crede." (Para que tu entendas, creia.) exposta no Sermão XLIII, é o grande exemplo daqueles que desejam crer no Deus religioso, ao passo que as elucubrações lógicas de homens doutos em Filosofia somente mostram um "deus filosófico" que é completamente distinto de caráter religioso:

7. Pensa, pois, neste pescador santo, justo, bom, pleno de Cristo, em cujas redes, lançadas por todo o mundo, havia de pescar este povo. Recorda o que digo: Temos um testemunho mais firme, o dos profetas ${ }^{26}$. Concede-me que naquela controvérsia o juiz seja o profeta. Que trazíamos entre as mãos? Tu dizias: "Que eu entenda para que creia". Eu dizia: "Para que tu entendas, creia". Surgiu a controvérsia; chegamos ao juiz, julgue o profeta; Na verdade, julgue Deus por meio do profeta. Ambos nos calamos. O que ambos dissemos, já foi ouvido. "tu disse: Que eu entenda para que creia". "Creia, digo eu, para que entendas". Responde o profeta: "Se não crerdes, vós não entenderdes" $" 27.28$

\section{Considerações finais}

O propósito deste texto foi o de apresentar uma reflexão pormenorizada e sistematizada a respeito da diferença existente entre um deus concebido por meio de um discurso filosófico completamente alheio às Escrituras Sagradas e o Deus religioso, isto é o Deus das Escrituras Sagradas. Buscamos, na primeira parte do texto, expor que o problema acerca da existência de um princípio ou ser, que é eterno, absoluto, gerador e mantenedor do mundo, e que pode ser reconhecido também como Deus, situa num terreno conflituoso e limítrofe entre a Filosofia e a Religião. Tanto uma quanto a outra, pode discorrer sobre Deus. Porém, nem sempre o discurso filosófico sobre as características

\footnotetext{
${ }^{25}$ BOEHNER, Philotheus.; GILSON, Étienne. História da Filosofia Cristã: Desde as Origens até Nicolau de Cusa. Tradução por Raimundo Vier, Petrópolis: Vozes, 1995. p. 389. Nossa tradução do trecho em latim: "Pois a graça da fé ilumina muitas coisas e também as divinas inspirações, não apenas nas coisas espirituais, mas nas corpóreas e nos estudos da filosofia."

${ }^{26}$ BÍBLIA SAGRADA, 2 Pt 1, 19.

${ }^{27}$ BÍBLIA SAGRADA, Is. 7, 9.

${ }^{28}$ AGOSTINHO, Santo. Sermones. In: Obras completas de San Agustín. Trad., introd. y notas de Miguel Fuertes y Moises Campelo. Madrid: La Editorial Católica/BAC, 1981, v. 7. Edición bilíngüe. p. 594, tradução nossa. (VII. Mementote ergo piscatorem sanctum, iustum, bonum, Christo plenum, ad cuius missa per mundum retia capiendus cum ceteris etiam populus iste pertinuit. Ergo mementote eum dixisse: Habemus certiorem propheticum sermonem. Da mihi ergo ad illam controversiam iudicem Prophetam. Quid inter nos agebatur? Tu dicebas: "Intellegam ut credam". Ego dicebam: "Ut intellegas crede". Nata est controversia, veniamus ad iudicem, iudicet Propheta, immo vero Deus iudicet per Prophetam. Ambo taceamus. Quid ambo dixerimus, auditum est. "Intellegam inquis, ut credam". "Crede, inquam ut intellegas". Respondeat Propheta: Nisi credideritis, non intellegetis.)
}

\begin{tabular}{|l|c|c|c|c|c|}
\hline intuitio & ISSN & Porto Alegre & Vol.7- No.2 & $\begin{array}{c}\text { Novembro } \\
2014\end{array}$ & p. 214-225 \\
\hline
\end{tabular}


Entre deuses e Deus: a diferença entre os deuses concebidos pela lógica filosófica e o Deus das Escrituras Sagradas de deus pode ser considerado como um discurso que se refere, necessariamente, ao Deus da fé. A fim de defender esta tese, expusemos excertos de filósofos modernos que, aparentemente, se retratam ao Deus da revelação. Feito isso, pudemos demonstrar que o discurso racional e filosófico, alheio à fé e a presença da Escritura, é incapaz de estabelecer qualquer relação direta com o Deus da fé. Em seguida, munidos dos excertos de outros filósofos, pudemos estabelecer a relação entre a possibilidade de um texto filosófico poder se remeter ao Deus religioso. As ferramentas que possibilitam esta união são a Escritura Revelada e a fé. Desta forma, sustentamos a tese de que o deus demonstrado filosoficamente não é o Deus da fé, pois o Deus da fé deve ser crido, e o ato de crer dispensa a demonstração e a contemplação através de postulados e definições lógicas.

\section{Referências}

AGOSTINHO, Santo. A Cidade de Deus, vol. III, Livros XVI a XXII. Trad. de J. Dias Pereira. Lisboa: Fundação Calouste Goulbekian, 1996.

. De Magistro. Trad., introd. e comentários por Bento Silva Santos. Petrópolis: Editora Vozes, 2009. (Coleção Textos Fundantes de Educação).

. Sermones. In: Obras completas de San Agustín. Trad., introd. y notas de Miguel Fuertes y Moises Campelo. Madrid: La Editorial Católica/BAC, 1981, v. 7. Edición bilíngüe.

ALCORÃ̃ SAGRADO. Tradução e notas de Samir El Hayek. São Paulo: Marsam, 1994.

BÍBLIA SAGRADA. Edição Pastoral. Trad., introd. e notas por Ivo Storniolo e Euclides Martins Balachin. São Paulo: Paulus, 2005.

BACON, Roger. Opera Maius. Disponível em < http://www.mlat.uzh.ch/MLS/ >. Acesso em: 23 out. 2013.

BOEHNER, Philoteus.; GILSON, Étienne. História da Filosofia Cristã: Desde as Origens até Nicolau de Cusa. Tradução por Raimundo Vier, Petrópolis: Vozes, 1995.

DESCARTES, René. Meditações sobre a Filosofia Primeira. Trad., nota prévia e revisão por Fausto Castilho. Campinas: Editora da Unicamp, 2004. Edição bilíngue.

DILTHEY, Wilhem, Os Tipos de Concepção de Mundo. Tradução de Artur Morão. Título Disponível em: <http://lusosofia.net >. Acesso em: 14 dez. 2013

GILSON, Étienne. The Future of Augustinian Metaphysics. In: M. C. D’ARCY et al. St. Augustine: His Age, Life and Thought. New York: Meridian Books, 1957.

GUERRERO, Rafael Ramón. Historia de la Filosofía Medieval. Madrid: Akal Ediciones, 2002.

HUME, David. História natural da religião. Trad., apresentação e notas por Jaimir Conte. São Paulo: Editora UNESP, 2005.

MAIMONIDES, Moisés. O Guia dos Perplexos: Parte I. Tradução por Uri Lam. São Paulo: Landy, 2003.

NIETZSCHE, Friedrich. Die Geburt der Tragödie. Unzeitgemässe Betrachtungen I-IV. Nachgelassene Schriften 1870-1873. Kritische Studienausgabe Herausgegeben von Giorgio Colli und Mazzino Montinari. Berlin: Walter de Gruyter, 1999. Band 1.

SPINOZA, Benedictus de. Ética. $2^{\text {a }}$ ed. Trad. e notas por Tomaz Tadeu. Belo Horizonte: Autêntica Editora, 2008. Edição bilíngue.

TEIXEIRA, Suellen Caroline. A ideia de liberdade em Descartes. 125f. Dissertação (Mestrado em Filosofia) Faculdade de Filosofia da Universidade Federal de Uberlândia, 2014.

WEISS-ROSMARIN, T. Judaísmo e Cristianismo: as diferenças. Trad. por Silvia Waldsztejn. São Paulo: Sêfer, 1996.

Recebido em: 29/09/2014

Aprovado para publicação em: 03/10/2014

\begin{tabular}{|c|c|c|c|c|c|}
\hline intuitio & ISSN & Porto Alegre & Vol.7- $\mathrm{N}^{\mathrm{o}} .2$ & $\begin{array}{c}\text { Novembro } \\
2014\end{array}$ & p. 214-225 \\
\hline
\end{tabular}

